\title{
THE CHALLENGES OF MEDICAL PRACTICE
}

VARIATIONS 
ECONOMIC ISSUES IN HEALTH CARE

General editors

Professor Gavin Mooney

Institute of Social Medicine

University of Copenhagen

2200 Copenhagen N, Denmark

\author{
Dr Alistair McGuire \\ Centre for of Socio-Legal Studies, \\ and Pembroke College \\ University of Oxford \\ Oxford OX2 6UD, England
}

The Challenges of Medical Practice Variations

Edited by Tavs Folmer Andersen and Gavin Mooney (1990)

Private Exchange and Public Interest

By John Forbes (1990)

Why Wait? Tackling Waiting Lists in the NHS

Edited by Stephen J. Frankel and R. R. West (1990)

Just Managing - Power and Culture in the NHS

By Stephen Harrison, David J. Hunter and Gordon Marnoch (1990)

Dental Care: An Economic View

By David Parkin and Brian Yule (1990) 


\title{
THE CHALLENGES OF
}

MEDICAL PRACTICE VARIATIONS

\author{
Edited by
}

\section{Tavs Folmer Andersen}

\author{
and
}

\section{Gavin Mooney}

Institute of Social Medicine

University of Copenhagen, Denmark

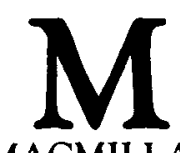

MACMILLAN

PRESS

Scientific \& Medical 
(C) The editors and contributors 1990

All rights reserved. No reproduction, copy or transmission of this publication may be made without written permission.

No paragraph of this publication may be reproduced, copied or transmitted save with written permission or in accordance with the provisions of the Copyright Act 1956 (as amended), or under the terms of any licence permitting limited copying issued by the Copyright Licensing Agency, 33-4 Alfred Place, London WC1E 7DP.

Any person who does any unauthorised act in relation to this publication may be liable to criminal prosecution and civil claims for damages.

First published 1990

Published by

THE MACMILLAN PRESS LTD

Houndmills, Basingstoke, Hampshire RG21 2XS

and London

Companies and representatives

throughout the world

Filmset by

Wearside Tradespools, Fulwell, Sunderland

British Library Cataloguing in Publication Data

The challenges of medical practice variations.

1. Medicine. Decision making. International aspects

I. Andersen, T. Folmer (Tavs Folmer) II. Mooney,

Gavin, 1943- III. Series

610

ISBN 978-0-333-47509-6

DOI 10.1007/978-1-349-20781-7

ISBN 978-1-349-20781-7 (eBook) 


\section{Contents}

Preface vii

The Contributors viii

1. Medical practice variations: Where are we? 1 Tavs Folmer Andersen and Gavin Mooney

2. Why do variations occur? 16

Klim McPherson

3. Variations in outcomes research

Leslie L. Roos, Ruth Brazauskas, Marsha M. Cohen and Sandra M. Sharp

4. Medical decision making and practice variation Albert G. Mulley, Jr.

5. Equity and variability in modern health care Gwyn Bevan

6. Measuring performance in the health care sector:

The whys and the hows

Alistair McGuire

7. The dog in the night-time: Medical practice variations and health policy Robert G. Evans

8. Variations from a lay perspective

Frede Vestergaard

9. On the need for outcomes research and the prospects for the evaluative clinical sciences

John E. Wennberg 
10. Promoting clinical policy change: Using the art to promote the science in medicine

Jonathan Lomas

11. Challenges facing modern health care

Gavin Mooney and Tavs Folmer Andersen

Index 


\section{Preface}

The objective of The Challenges of Medical Practice Variations is to stimulate debate about the research and policy implications of the variations in medical practices from various perspectives, including efficiency, equity and effectiveness, but also health policy, health service management, clinical practice and the role of the medical profession. The focus is international but, in particular, European.

The book has been a genuinely joint process not only by the editors, but also by all the contributors. That is wholly appropriate, as it is our view that the challenge of medical practice variation does not only lie with the medical profession, nor only with medical research: variation involves many facets and many disciplines and professions.

The publication of this book, which is the first dealing solely with the topic of medical practice variation, is also the joint product of the efforts of the staff and board of the CCC - the Copenhagen Collaborating Center for the Study of Regional Variations in Health Care. To all of them, past and present, we owe a special debt.

The process involved in preparing the book may be worth mentioning. As editors we drew up a series of outlines for the contributions we sought and then got the agreement of the authors we had selected to write them. We wrote the introductory chapter and circulated this to all the contributors. They submitted synopses of their chapters, on which we commented, and then wrote their chapters which again we commented on before this final product emerged.

Finally, we should like to thank Maria Kapitzke and Annelise Nielsen for their secretarial assistance in the preparation of manuscripts.

Copenhagen, May 1989

T.F.A.

G.M. 


\section{The Contributors}

Tavs Folmer Andersen

Copenhagen Collaborating Center

Institute of Social Medicine

University of Copenhagen

Panum Institute

Blegdamsvej 3

2200 Copenhagen $\mathrm{N}$

Denmark

\section{Gwyn Bevan}

Department of Community Medicine

St. Thomas's Hospital

London SE1 7EH

England

\section{Ruth Brazauskas}

Department of Business Administration

Faculty of Management

University of Manitoba

Winnipeg, Manitoba R3T 2N2

Canada

\section{Marsha M Cohen}

Department of Community Health Sciences

Faculty of Medicine

University of Manitoba

Winnipeg, Manitoba R3T 2N2

Canada

\section{Robert G Evans}

Department of Economics

University of British Columbia

400-2194 Health Sciences Mall

Vancouver, B.C. V6T 1 Z6

Canada 


\title{
Jonathan Lomas
}

Department of Clinical Epidemiology and Biostatistics

Faculty of Medicine

McMaster University

Hamilton, Ontario L8S 4M4

Canada

\author{
Alistair McGuire \\ Centre for Socio-Legal Studies, and Pembroke College \\ University of Oxford \\ Oxford OX2 6UD \\ England
}

\section{Klim McPherson}

Department of Community Medicine

Oxford University

Gibson Labs Radcliffe Infirmary

Oxford OX2 6HE

England

\section{Gavin Mooney}

Institute of Social Medicine

University of Copenhagen

Panum Institute

Blegdamsvej 3

2200 Copenhagen $\mathrm{N}$

Denmark

\section{Albert G Mulley, Jr.}

General Internal Medicine

Massachusetts General Hospital

Fruit Street

Boston, MA 02114

USA

\section{Leslie L Roos}

Department of Business Administration

Faculty of Management

University of Manitoba

Winnipeg, Manitoba R3T 2N2

Canada 


\section{Sandra M Sharp}

Department of Business Administration

Faculty of Management

University of Manitoba

Winnipeg, Manitoba R3T 2N2

Canada

Frede Vestergaard

Berlingske Weekendnews

G1. Mønt 1

1147 Copenhagen $\mathrm{K}$

Denmark

\section{John E Wennberg}

Department of Community and Family Medicine

Dartmouth Medical School

Hanover, NH 03755

USA 